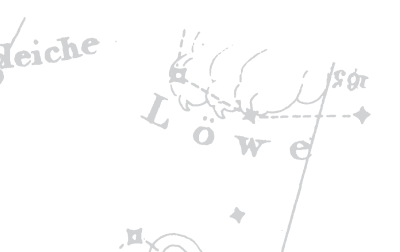

\title{
Literatura COMPARADA
} NO BRASIL: PESSOAS,

\section{PERSONAS, PERSONAGENS}





\title{
História, ensaio, intervalo Os lugares da crítica e da literatura em João Alexandre Barbosa ${ }^{1}$
}

\author{
EDUARDO STERZI \\ Universidade Estadual de Campinas
}

RESUMO: EM ENTREVISTA CONCEDIDA SEIS ANOS ANTES DE SUA MORTE, OCORRIDA EM 2006, O CRÍTICO LITERÁRIO JOÃO ALEXANDRE BARBOSA EXPLICITARIA AO AUTOR O DESEJO DE ESCREVER UM "ENSAIO DE HISTÓRIA DA LITERATURA BRASIIEIRA", QUE PERMANECEU COMO PROJETO. NESTE ARTIGO, O AUTOR PROCURA CONFERIR LEGIBILIDADE À OBRA "NÃO-LEGIVEL", PORQUE NÃO EFETIVAMENTE ESCRITA, DO CRÍTICO BRASILEIRO, BUSCANDO VÊ-LA COMO UMA ESPÉCIE DE "MOTOR SECRETO" DE SEU PERCURSO CRÍTICO.

ABSTRACT: IN AN INTERVIEW GIVEN IN 2000, THE BRAZILIAN CRITIC JOÃO ALEXANDRE BARBOSA, DEAD IN 2006, MANIFESTED HIS WISH OF WRITING AN "ESSAY ON THE HISTORY OF BRAZILIAN LITERATURE", WHICH HAS NEVER BEEN ACTUALLY COMPLETED. THE AUTHOR OF THIS ARTICLE AIMS TO GIVE LEGIBILITY TO THIS "NON-LEGIBLE" (BECAUSE NEVER EFFECTIVELY WRITTEN) WORK BY THE BRAZILIAN CRITIC, SHOWING IT AS A KIND OF "SECRET ENGINE" THAT HAS EMPOWERED HIS CRITICAL PATH.

PALAVRAS-CHAVE: CRITTICA LITERÁRIA - HISTÓRIA LITERÁRIA - LITERATURA NO BRASIL KEY-WORDS: LITERARY CRITICISM - LITERARY HISTORY - BRAZILIAN LITERATURE

\footnotetext{
${ }^{1}$ Este ensaio - que teve uma primeira versão publicada em K: Jornal de crítica, IV (set. 2006) - é constituído por segmentos de um estudo mais amplo, ainda em andamento, sobre a obra crítica de João Alexandre Barbosa.
} 
e désir de faire excite le pouvoir de faire qui tue le désir.

Paul Valéry, Cahiers (citado por João Alexandre Barbosa em Alguma crítica)

Não apenas consciência e canto - mas ciência exilada.

João Alexandre Barbosa, $A$ metáfora crítica

No prefácio escrito em 1989 para a tradução francesa de seu Infanzia e storia, Giorgio Agamben anota:

Toda obra escrita pode ser considerada como o prólogo (ou, melhor, como a cera perdida) de uma obra nunca escrita, que permanece necessariamente tal porque, com respeito a essa, as obras sucessivas (por sua vez, prelúdios ou decalques de outras obras ausentes) não representam senão estilhaços ou máscaras mortuárias. A obra ausente, mesmo não sendo exatamente situável numa cronologia, constitui assim as obras escritas como prolegomena ou paralipomena de um texto inexistente ou, em geral, como parerga que encontram o seu verdadeiro sentido somente junto a um ergon ilegível. (AGAMBEN, 2001)

Inspirando-nos nessa passagem de Agamben, podemos nos perguntar qual seria o "texto inexistente" do qual os textos efetivamente escritos por João Alexandre Barbosa funcionariam como prólogos ou pós-escritos. Trata-se, aqui, de conferir legibilidade - ainda que precária, relampejante - ao "ergon ilegível" que, construindo-se fantasmaticamente ao lado ou por trás dos textos que de fato se dão a ler, conservaria, em latência, o "verdadeiro sentido" dessa obra crítica. A indagação é pela potência pré ou mesmo contratextual que se oculta na obra de João Alexandre Barbosa: em alguma medida, pela teoria - pela unidade, embora tensa, de pensamento - que atravessa e traveja o conjunto heterogêneo da sua obra. Que descuvrement opera clandestinamente nos interstícios da obra realmente produzida e oferecida ao leitor? Que inoperosità (para lembrar um termo-chave de Agamben) nela se esconde, funcionando como uma espécie de motor secreto da escrita? Que inação que renúncia - zela pela discreta, mas persistente, potência da obra? Em suma: o que não pôde ser escrito para que a obra tivesse a força que tem?

Numa entrevista concedida em 2000 (portanto, quando já se desenhava aquela que seria a fase final de sua obra), João Alexandre Barbosa dizia que seu "projeto atual mais amplo" - "e", acrescentava, "mais secreto" - era 
"trabalhar com a história da literatura brasileira" num ensaio para o qual planejava "retomar", num jogo irônico com a tradição crítico-historiográfica iniciada no romantismo, "um velho título" de Varnhagen, "que alguns encaram como fundador da história da literatura brasileira" (STERZI, 2000: 96). Tratava-se do título da introdução do Florilégio da poesia brasileira, "Ensaio histórico sobre as letras no Brasil" - que João Alexandre Barbosa pretendia atualizar no seu "Ensaio de história da literatura brasileira". Se até então ainda não começara a escrever o ensaio, era porque, conforme admitia, sentia dificuldades (dificuldades teóricas, para ser mais preciso, ou antes, podemos dizer já interpretando, sentia a teoria como dificuldade, a teoria como inoperosidade) em ultrapassar o momento inicial da intuição de um estado de coisas e, enfim, dar forma textual a essa intuição: "É muito difícil, mas é o que estou querendo fazer. [...] Essa idéia do ensaio: ensaio e insight... Tenho pensado muito sobre isso, mas ainda me falta elaborar aquele elemento de tensão fundamental que amarra as coisas". Na verdade, uma hipótese já se insinuava, o discernimento de um processo fundamental para a constituição da história da literatura brasileira, o qual, no entanto, era e é freqüentemente menosprezado nas narrativas já estabelecidas dessa história - a tradução:

Tenho pensado que talvez seja interessante o problema da tradução. Porque a tradução talvez dê conta de uma grande parte da cultura brasileira. Este é um país de traduções. Nós traduzimos o tempo todo. Começamos traduzindo. Nisso, o Barroco é extraordinário... Gostaria de ter força para ver isso na literatura brasileira, o que é difícil. Mas é um prazer. (STERZI, 2000)

$\mathrm{Na}$ mesma entrevista, João Alexandre Barbosa dava uma pista acerca da insuficiência contra a qual pretendia escrever seu "Ensaio de história da literatura brasileira". Ao comentar a introdução que escrevera para a reedição de Homens e coisas estrangeiras, de José Veríssimo, dizia:

É um livro notável, por tudo: pelos erros, pelas más leituras, mas o que impressiona é como ele estava em dia com o que se fazia. Entretanto, quando escreve a História da literatura brasileira, parece que não leu essas coisas. Ele se apequena. (STERZI, 2000: 90) 
Veríssimo - que lia Nietzsche, que lia John Ruskin, que lia Tolstói, seus contemporâneos -, ao passar à escrita da sua História (de resto, avançada em relação ao "determinismo e evolucionismo de Sílvio Romero"), parece esquecer todas essas leituras, leituras que deveriam levá-lo a um repensamento da concepção de história, e, pois, de história literária. Esse hiato entre, digamos, conhecimento teórico e prática historiográfico-literária não é, contudo, exclusividade de José Veríssimo; pelo contrário, "isso é muito comum”, diz João Alexandre Barbosa. "Por isso", acrescenta, "os arrojos da vanguarda são importantes para uma nova história da literatura brasileira. Temos que repor, propor, questionar, em termos não provincianos, mas questionar mais alto” (STERZI, 2000).

O leitor decerto já terá depreendido que é nesse projeto "secreto" de "trabalhar com a história da literatura brasileira" que se encontra, a meu ver, o "ergon ilegível" da obra de João Alexandre Barbosa. Não parece dever-se apenas às circunstâncias o fato de que o ensaio - salvo engano - não tenha sido escrito nos seis anos que separam a entrevista da morte do crítico. Gostaria de sugerir que permaneceu inescrito - e rigorosamente ilegível - porque corresponderia à explicitação integral de um trabalho, em alguma medida, efetivamente realizado ao longo de todo o percurso crítico de João Alexandre Barbosa, o qual, entretanto, tirava muito de sua força precisamente de sua renitente não-explicitação, ou, antes, de sua explicitação sempre fragmentária, prismática, como convém à predileção do crítico pela forma do ensaio. Daí que, menos que lembrar o título de Varnhagen, o título pretendido para o "Ensaio de história da literatura brasileira" lembrava o título de um texto escrito pelo próprio João Alexandre Barbosa nos primeiros anos de sua atividade como crítico: refiro-me ao "Ensaio de historiografia literária brasileira", apresentado como tese ao II Congresso Brasileiro de Crítica e História Literária, realizado em Assis, em 1961, e publicado no ano seguinte, com modificações, numa revista de Recife, depois de ter integrado, no mesmo ano, os anais do Congresso (hoje, o texto encontra-se no livro Opus 60 , recolha de textos de juventude saída em 1980). Nesse ensaio, espécie de precoce ajuste de contas com a tradição crítico-historiográfica brasileira, João Alexandre Barbosa mobilizou um amplo conhecimento de estudos literários internacionais para melhor revelar os limites dos estudos brasileiros (sempre disposto também a realçar os limites dos estudos internacionais). Com acerto, percebe, por exemplo, que é precisamente a "tendência à não-historicidade" 
da crítica de T. S. Eliot que lhe permite "livrar a História Literária do excesso historicista que a contaminou [...] por todo o século XIX" (BARBOSA, 1980: 40). Era esse "excesso" que conduzia ao

[...] estabelecimento dos "panoramas históricos", das "situações político-sociais", que iniciam sempre os manuais clássicos de História da Literatura, sem que os ditos panoramas de situações funcionem, de modo indissolúvel, na análise das próprias obras e autores.

Desde esse ensaio, a crítica já aparece como a instância responsável pela mediação entre história e literatura, permitindo ao estudioso "inserir o fenômeno literário na História" e "o sentido desta naquele", escapando, pois, à "monótona relação de obras e autores" (BARBOSA, 1980: 32).

Não deixa de ser curioso que um autor para quem o interesse pela história literária foi constante ao longo de toda a obra tenha resistido tão bravamente ao ímpeto totalizador inerente à própria noção de história literária. Se João Alexandre Barbosa não produziu nenhuma obra nos moldes da Formação da literatura brasileira, certamente não foi por falta de conhecimento ou de competência para tal. Apenas sua estratégia crítica era bem outra. O título do projetado "Ensaio de história da literatura brasileira" não deixa dúvidas quanto à renúncia à totalização previsível ao se experimentar a perspectiva histórico-literária. O que significa, afinal, propor um ensaio de história literária? Não menos que estabelecer uma zona de tensão para o pensamento da literatura, uma zona em que a suposta estabilidade proporcionada pelo modelo histórico-literário é posta à prova pela forma do ensaio.

Não por acaso, João Alexandre Barbosa não foi somente um exímio ensaísta, como também, sem ênfase (como de seu hábito), um teórico do ensaio. É assim que, já entre seus primeiros textos, encontramos uma resenha de Tese e antitese, de Antonio Candido, em que o exame do livro dá a ocasião para considerações mais gerais sobre a forma nele exercitada, delineando-se aí uma compreensão do ensaísmo que será radicalizada nas décadas seguintes, tanto na teoria como na prática:

O ensaio literário é, antes de mais nada, uma forma de indagação perseguida por entre idéias, palavras, estruturas. Saber ler a contradição por sob as afirma- 
ções mais evidentes, valorizar elementos aparentemente dispersos, configurar numa página o sentido oculto de uma descoberta, são algumas das diretivas do ensaio literário. E todo esse jogo da inteligência requer muito mais do que simples erudição ou virtuosismo verbal: funda-se no equilíbrio mas ultrapassao pela sugestão. Por isso mesmo, há uma imprescindível dialética intrínseca do ensaio que lhe comunica o que se poderia chamar de tendência à superação. É esta dialética que confere ao gênero o seu vigor, a sua resistência ao levianamente afirmativo ou negativo. A sua órbita é antes a da caça ao objeto, sem a qual o arranjo verbal ou ideológico resseca na fonte, transformado em informação pura e simples. Não se escreve ensaio sobre aquilo que não preocupa sob a forma de matéria viva, operante, capaz de germinar idéias, exigir elucidações. (BARBOSA, 1980: 95)

Em um texto escrito muitos anos depois, outra vez sobre Antonio Candido, essa "caça ao objeto", característica do ensaio, retornará, sem nenhum resquício de ilusão positivista quanto à estabilidade da meta ou do método, quando se diz que o "ensaísmo crítico" se define por suas "incertezas", isto é, por sua "busca" (BARBOSA, 2002: 143). Em outro texto, não surpreende que se encontre a "essência do ensaio" numa ausência: na "ausência de objetos fixos ou obsessões de certeza que se oporiam à própria definição do gênero" (BARBOSA, 1999: 34). Seria o caso de recordar, aqui, o que diz Agamben no prefácio de Stanze: "Como toda autêntica quête, a quête da crítica não consiste no reencontrar [ritrovare] o próprio objeto, mas no assegurar as condições da sua inacessibilidade" (AGAMBEN, 1993, p. XIII).

No ensaio, a linguagem - como já notaram diversos analistas da forma aspira a uma autonomia que, porém, jamais pode conquistar plenamente. Com razão, Schlegel - lembrado por Lukács em $A$ alma e as formas - definiu o ensaio como "poesia intelectual” (LUKÁCS, 1991: 37). Como diz João Alexandre Barbosa: "Cada palavra, cada invenção frásica pode sugerir uma vereda ainda não explorada, insinuando novas descobertas, atraindo relações imprevistas" (BARBOSA, 1980: 96). À linguagem e seus jogos, o ensaísta atribui o poder de duvidar dos sistemas. Daí que a "dialética intrínseca" do ensaio assim se deixe descrever: "Por sob a aparente tranqüilidade de um texto, de um autor, de uma idéia firmada, o sentido do ensaio exige o contrapeso, a oposição, aquilo que lateja por trás dos esquemas" (BARBOSA, 1980: 96). Luiz Costa 
Lima, partindo das considerações de Lukács, chama a atenção para a posição intervalar do ensaio, entre forma e sistema: "Sem ser absolutamente forma mas pertencente ao que a forma pré-ocupa, o ensaio se singulariza pelo intervalo em que permanece"2 (COSTA LIMA, 2005: 99.

Intervalo, como se sabe, é uma palavra fundamental do léxico crítico de João Alexandre Barbosa. A tensão - o intervalo - é o lugar do crítico. Aspirar a um outro lugar, mais seguro, é rejeitar a especificidade da sua tarefa. Ao apontar a novidade do método crítico de Antonio Candido, João Alexandre Barbosa diz:

Não é o crítico que transforma o elemento externo em interno mas, sim, o próprio processo de construção da obra, a ele cabendo a habilidade de fisgar a transformação, que é sempre o resultado de uma prática analítica ancorada na consciência da linguagem literária. Para o crítico, não há [...] preferência possível: a sua atividade se passa por entre as tensões suscitadas pelo movimento de internalização que é a obra literária, a não ser que, ao invés de crítico literário, ele se identifique, por exemplo, como sociólogo, psicólogo ou historiador. (BARBOSA, 2002: 142)

O intervalo não é, para João Alexandre Barbosa, um conceito capaz de apaziguar a leitura, mas o nome mesmo da ambígua posição que cabe ao crítico. Devido à limitação de espaço, não se vai esmiuçar aqui todo o alcance da idéia de intervalo na sua obra; restrinjo-me a citar a passagem do prefácio de $A$ leitura do intervalo em que o crítico resume essa noção:

A idéia é bastante simples: na leitura da literatura, entre os significados (históricos, sociais, psicológicos) e a maneira de sua textualização, o leitor procura apreender relações e tende a construir pares, tais como literatura e história, literatura e sociedade, literatura e psicologia. O que se propõe basicamente é que se busque apreender a relação a partir do próprio movimento interno de configuração do signo literário, operando-se a aglutinação dos significados pela

\footnotetext{
2 “A crítica reside em um certo intervalo. Para dizê-lo com o próprio Schlegel, nela se concretiza o dilema entre ater-se a um sistema ou não contar com sistema algum” (COSTA LIMA, 2005: 215).
} 
intensidade dos significantes textuais, fazendo desaparecer, nos limites, a prevalência isolada dos significados, sem que se esvaia a sua existência concreta. A esta leitura entre os dados da realidade e suas representações é o que aqui se chama de leitura do intervalo. O intervalo, portanto, não é um vazio: é antes aquele tempo/espaço em que a literatura se afirma como literatura sendo sempre mais do que literatura porque apontando para esferas do conhecimento a partir das quais o signo literário alcança a representação. Deste modo, a leitura do intervalo o que, na verdade, almeja é uma apreensão dos significados pela via de sua tradução literária, o que significa dizer que, neste caso, não há um antes ou um depois: o histórico, o social e o psicológico, no poema ou no romance, é literatura e, sendo assim, caminha-se em direção de uma aglutinação. Não mais literatura $e$ mas literatura/história, literatura/sociedade, etc. (BARBOSA, 1990: 11-12).

Recorde-se, à luz dessa consideração sobre o intervalo, a possível escolha da tradução como metáfora crítica em torno da qual pensar o inescrito "Ensaio de história da literatura brasileira". A tradução não é menos que uma maneira de assumir a centralidade do intervalo na literatura, aspirando àquela "cicatriz razoavelmente tecida" que, no texto sobre Tese e antítese, é apresentada como a meta do "verdadeiro ensaio literário" (BARBOSA, 1980: 96).

Toda a obra de João Alexandre Barbosa implica um insistente repensamento da mímesis. Daí que se leia num de seus últimos ensaios:

Desde os inícios das reflexões poéticas, desde, pelo menos, Platão e Aristóteles, a questão da representação é a contraparte teórica da própria operação poética. E não poderia ser de outra forma de vez que, se instaurando no espaço ficcional, mas traduzindo elementos obtidos nas relações sociais, o poético tem a sua singularidade em operar intensamente nos intervalos entre a experiência e a representação da experiência pelos deslocamentos possíveis da linguagem. (BARBOSA, 2002: 14-15)

(Frisem-se, na última frase, as idéias de intervalo - o espaço entre experiência e representação, mundo e linguagem - e tradução - a operação de passagem por sobre o intervalo.) É exemplar desse repensamento da mímesis o discernimento daquele que seria o princípio ou processo fundamental da 
poesia de João Cabral, o qual João Alexandre Barbosa define como sendo o de imitação da forma (em oposição declarada à imitação "do conteúdo" ou "da realidade"): dito de modo sumário, Cabral não se interessa por imitar, com e em sua poesia, determinados objetos, mas, sim, a forma, isto é, o modo de ser desses objetos, a linguagem, em suma, desses objetos.

O que lhe ensinam as danças, as cabras mediterrâneas e nordestinas, os cemitérios alagoano, paraibano ou pernambucano, as frutas do Nordeste, as "paisagens com cupim" do litoral pernambucano, as praias ensolaradas do "Nordeste de Pernambuco" é, sobretudo, uma forma de leitura da realidade. É esta forma que ele imita pela linguagem do poema, não o que resta de dados colhidos pela sensibilidade. (BARBOSA, 1975: 158-159)

Em resumo: "A sua é antes uma imitação da forma do que de conteúdos dados pelo real" (BARBOSA, 1975: 153). Só se alcança algo que pode ser compreendido como "imitação do real" à medida que se aprende, com os objetos, seus modos de "realização", seus modos de "tornar real" (e, antes, de tornar-se real) (BARBOSA, 1975: 158). Trata-se de, "operando um incessante direcionamento para a linguagem", aprender "com os objetos uma forma de imitar a realidade" (BARBOSA, 1975: 153). Trata-se de "atingir uma objetividade que, sendo lingüística, é, por isso mesmo, no espaço do texto, mais real' (BARBOSA, 1975: 167).

Daí a conclusão drástica, no texto concebido originariamente como introdução teórica a seu trabalho sobre Cabral: "Só é realidade do texto aquilo [...] que é, antes de mais nada, texto, Literatura” (BARBOSA, 1974: 12). Isto se explica pelo fato de que "é antes pela negação do que pela aceitação que o poema arma a sua rede de respostas à realidade” (BARBOSA, 1974: 41). O poema moderno - que, neste sentido, apenas ousa levar às últimas conseqüências o princípio da negatividade inerente a toda poesia e a toda arte faz-se registro de algo que não é menos que uma "crise da realidade" (BARBOSA, 1974: 42). A solução para o crítico passa por colocar em questão as concepções tradicionais de historicidade, e, antes, mesmo de temporalidade:

Não se trata mais de falar em adequação entre literatura e sociedade como resultado de suas relações mas em incluir, como elemento fundamental de caracteriza- 
ção, quer da literatura quer da sociedade, os momentos de inadequação através dos quais o poético se expande na criação de um espaço e de um tempo capazes de romper com os estreitos limites de uma diacronia evolutiva de causa e efeito.

João Alexandre Barbosa nota que, em países como o Brasil - "países em que as pressões de ordem histórica, política e econômica impossibilitam qualquer leitura de causa e efeito na ordem intelectual e artística" (BARBOSA, 1974: 27) -, vem cabendo às vanguardas as revisões de obras e autores do passado imprescindíveis a uma renovação da historiografia literária - obras e autores "para os quais o futuro é [...] determinado por uma espécie de leitura anacrônica ou, melhor dizendo, sincrônica se referida ao presente situado do leitor" (BARBOSA, 1974: 27-28). Na verdade, somente essa leitura anacrônica ou sincrônica pode ser dita, com razão, uma "leitura inexoravelmente histórica": porém, bem se entenda, estamos aqui diante de "uma história que não elide a poeticidade porque sabe que a sua é uma natureza sobretudo discursiva e, portanto, informada por todas as ambigüidades do discurso" (BARBOSA, 1974: 28). Em resumo: "Não uma história de datas, fatos e personagens, mas aquela que põe sob suspeita [...] a própria capacidade de sua representação". O que se afirma aqui é a necessidade de uma "poética da história", na qual o crítico ("ou seja lá qual for o seu nome": o estatuto do estudioso de literatura, enquanto ser intervalar, torna-se inseguro) "existe, antes de mais nada, num intervalo de tensões entre a realidade e a linguagem de sua representação”. É certo que a leitura desse intervalo é "uma leitura insegura, instável, sempre en abîme". Porém (é a pergunta que João Alexandre Barbosa se faz, para logo respondê-la ele mesmo), que literatura e que sociedade podem ser ditas completamente seguras, estáveis, "sem sobressaltos abismais"? "Talvez" - diz - "as totalitárias", e dessas ele se dispensou de tratar.

\section{Referências Bibliográficas}

AGAMBEN, Giorgio. "Experimentum linguae". In: Infanzia e storia: distruzione dell'esperienza e origine della storia. 2. ed. accresciuta. Torino: Einaudi, 2001. . "Prefazione". In: Stanze: la parola e il fantasma nella cultura occidentale. 2. ed. Torino: Einaudi, 1993. 
BARBOSA, João Alexandre. "Ensaio de historiografia literária brasileira". In: Opus 60: ensaios de crítica. São Paulo: Duas Cidades, 1980.

. "Convite à controvérsia". In: Opus 60: ensaios de crítica. São Paulo: Duas Cidades, 1980.

. "O método crítico de Antonio Candido". In: Alguma crítica. Cotia: Ateliê, 2002.

. "Pequenas variações sobre o ensaio". In: Entre livros. Cotia: Ateliê, 1999.

. "Prefácio". In: A leitura do intervalo: ensaios de crítica. São Paulo: Iluminuras e Secretaria de Estado da Cultura, 1990.

. "Literatura e sociedade do fim do século". In: Alguma crítica. Cotia: Ateliê, 2002.

- A imitação da forma: uma leitura de João Cabral de Melo Neto. São Paulo: Duas Cidades, 1975.

. "Exercícios de definição". In: A metáfora crítica. São Paulo: Perspectiva, 1974.

COSTA LIMA, Luiz. Limites da voz (Montaigne, Schlegel, Kafka). 2. ed. Rio de Janeiro: Topbooks, 2005.

LUKÁCS, Georg. L'anima e le forme. Trad. Sergio Bologna. Milano: SE, 1991.

STERZI, Eduardo. "João Alexandre Barbosa: é preciso arriscar”. Brasil/ Brazil, XXIII 2000. p. 96. 
